OCCASIONAL REVIEW

\title{
Promotion of smoking cessation in developing countries: a framework for urgent public health interventions
}

\author{
A S M Abdullah, C G Husten
}

Thorax 2004;59:623-630. doi: 10.1136/thx.2003.018820

The rapid rise in smoking in many developing countries will have devastating consequences; by 2030 the developing world is expected to have 7 million deaths annually from tobacco use. Many smokers express a desire to quit, but they often fail because they are addicted to tobacco. Although a number of cessation aids are now available in the developed world, their applicability and affordability in developing countries is less clear. Successful interventions will require many stakeholder groups to take action at the local, national, and international levels. We discuss smoking cessation as a means of reducing disease burden, examine factors that may limit the promotion of smoking cessation in developing countries, and propose a framework for public health action. This framework should comprise intervention with healthcare professionals, strengthening national commitment, development of a model for developing countries, changing the social acceptability of smoking, strengthening community participation, integration of smoking cessation with other healthcare services, specifying the role of healthcare professionals, development of guidelines, mobilisation of the business community, provision of financial incentives, establishing population specific smoking cessation services, increased collaboration between countries, and development of international initiatives.

See end of article for authors' affiliations

Correspondence to Dr A S M Abdullah, Department of Community Medicine, The University of Hong Kong, 5/F

Academic Block, New Medical Complex, 21

Sassoon Road, Pokfulam, Hong Kong SAR; asm. abdullah@graduate.hku. $\mathrm{hk}$

Received

12 November 2003

Accepted 17 March 2004
D eveloping countries (those with low and middle incomes) whose current population totals some 4.9 billion $^{1}$ face a rapidly growing epidemic of tobacco use; rates began increasing in these countries in the early 1970s (fig 1). ${ }^{2}$ In 1995, 82\% of the world's 1.1 billion smokers lived in the developing world ${ }^{2}$ where the prevalence of smoking in men and women averaged $49 \%$ and $9 \%$, respectively. ${ }^{3}$ In 2000, 4.83 million premature deaths in the world were attributable to smoking, with 2.41 million deaths in developing countries. ${ }^{4}$ The World Health Organization (WHO) predicts that, if current patterns of consumption continue, more than 500 million people alive today will be killed by tobacco by 2030. ${ }^{3}$ Thus, tobacco control-particularly cessation interventions-will need to be a priority for policy makers in developing countries if a substantial impact is to be made within the next few decades on the morbidity and mortality caused by tobacco. Unfortunately, many barriers must be overcome for cessation strategies to be implemented broadly and successfully within a comprehensive approach to tobacco control.

\section{Importance of smoking cessation in} reducing disease burden

Smoking cessation is a priority for preventing disease and reducing its burden. ${ }^{5-8}$ At any age, quitting confers substantial and immediate health benefits including reduced cardiovascular disease risk, ${ }^{9}$ improved lipid profiles and platelet reactivity, ${ }^{10}$ and reduced risk of stroke $^{9}$ and smoking attributable cancers. ${ }^{10}$ The World Bank suggests that, if adult consumption were to decrease by $50 \%$ by the year 2020 , approximately 180 million tobacco related deaths could be avoided. ${ }^{3}$ Thus, promotion of smoking cessation and treatment of tobacco dependence can have a great impact in reducing the burden of disease ${ }^{4}$ and improving population health.

According to the Commission on Macroeconomics and Health (a WHO publication), smoking is on a short list of specific conditions-including HIV/AIDS, malaria, tuberculosis, childhood infectious disease, maternal and perinatal conditions, and micronutrient deficiencies-that need to be a priority in low income countries to save millions of lives, reduce poverty, spur economic development, and promote global security. ${ }^{11}$ In addition, cessation interventions are described specifically in the draft Framework Convention on Tobacco Control (FCTC); signing the FCTC and its ratification will obligate countries to work on cessation as part of a comprehensive effort in tobacco prevention and control. ${ }^{12}$

\section{Need for interventions to increase cessation}

Tobacco dependence is recognised as a disease in the WHO's International Classification of Diseases $(\text { ICD-10 })^{13}$ and the American Psychiatric Association's Diagnostic and Statistical Manual (DSM-IV). ${ }^{14}$ In developed countries a large proportion of smokers want to stop smoking ${ }^{15}$ and many try to stop, ${ }^{16}$ but the corresponding proportions in developing countries are low. ${ }^{17-19}$ Quit rates (the proportion of ever smokers who have quit) are also low in many developing countries. ${ }^{2}{ }^{3}$ Smokers who try to quit often find it difficult because of the addictive properties of nicotine. ${ }^{19} 20$ Because of the low rates of quitting and the inherent difficulties in stopping, governments need to encourage smokers to quit and to provide more assistance to those who need help. 


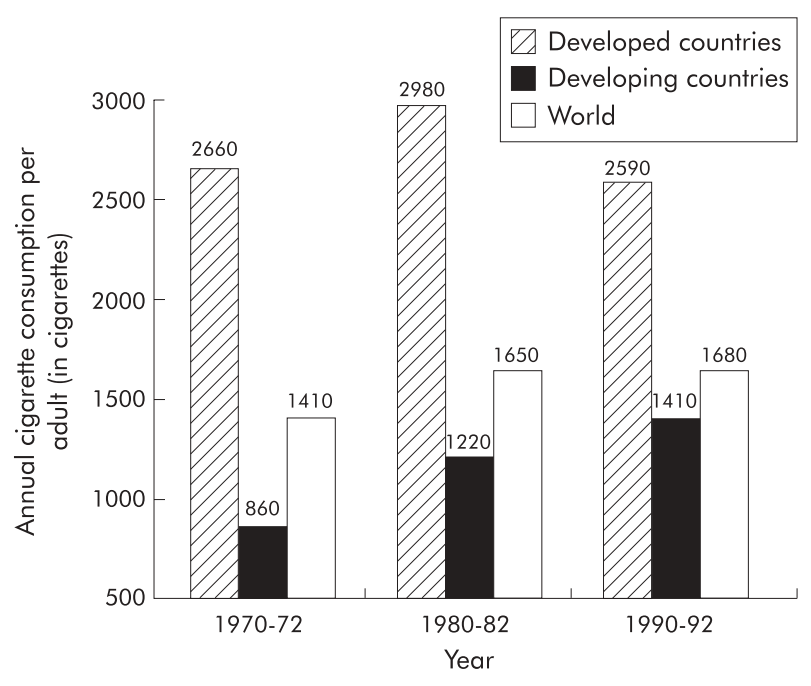

Figure 1 Trends in per capita adult (age 15 years and over) cigarette consumption in the world and in developed and developing countries, $1970-2$ to $1990-2$.

\section{Evidence base for effective interventions}

The evidence base for both the effectiveness and cost effectiveness of clinical smoking cessation interventions is strong in Europe ${ }^{21}$ and the US. ${ }^{62-24}$ A similar evidentiary base is not available for developing countries, ${ }^{25}$ but the recommended clinical interventions have been shown to work in diverse populations in the US (although the extent to which tailoring could increase effectiveness has not been well studied)..$^{21}$

In the US there is also a strong evidence base for the effectiveness of community based and population based interventions such as running sustained mass media campaigns, raising tobacco prices, reducing the cost of treatment, and establishing telephone quit lines. ${ }^{26}{ }^{27}$ Some data on these interventions are also available from other countries, particularly for countermarketing campaigns, complete bans on advertising, and taxation. ${ }^{28}{ }^{29}$ Incorporating some of these interventions within national tobacco control strategies should be feasible in developing countries. ${ }^{26}{ }^{30}$ Brazil $^{31}$ and Thailand ${ }^{32}$ have successfully implemented such interventions within the national tobacco control programme.

In low and middle income countries a $10 \%$ increase in price decreases consumption by an estimated $8 \%,{ }^{29}$ an effect double that seen in high income countries. This reduction represents a combination of fewer young people starting to smoke, fewer cigarettes being smoked by those who continue to smoke, and increased cessation. ${ }^{27}{ }^{29}$ Tax increases have the added benefit of providing resources to the government, which may be particularly important in resource poor countries; such funding could help to support other tobacco prevention and control activities. ${ }^{29}$

Policies to establish smoke free indoor air provide a social environment that encourages non-smoking. Smoke free policies have been clearly shown to decrease cigarette consumption, and some data suggest that smoke free policies may increase cessation. ${ }^{26}{ }^{33}$ Clean indoor air restrictions are moderately feasible but may be harder to enforce in developing countries because of a smaller formal labour sector. $^{34}$ Decreasing out-of-pocket costs for cessation treatment increases the number of smokers who try to quit as well as the number of successful quitters, ${ }^{27}$ this cost barrier may be particularly important in developing countries. The studies are all from the US, but several were done among low income smokers. Advertising bans may reduce the cues to smoke, ${ }^{25}$ and total bans on advertising reduce consumption while partial bans have no effect. ${ }^{28}$ Because control of smuggling preserves revenue from tobacco taxation and keeps tobacco prices higher (thereby reducing consumption), ${ }^{35}$ establishing such control is a highly relevant strategy for low income countries. ${ }^{34}$ In addition, countermarketing campaigns have been shown to increase cessation, ${ }^{27}$ and at least four countermarketing studies outside the US have also demonstrated their effectiveness in increasing cessation. ${ }^{28}$

\section{SMOKING CESSATION AND THE DEVELOPING WORLD}

The developed and developing countries vary greatly in the proportion of their smokers who have quit smoking. For example, in developed (high income) countries 30\% of men were former smokers in 1993, while in 1996 less than 4\% of Chinese smokers were former smokers. Only 5\% of Indian men had quit in 1992-4, and only 10\% of Vietnamese men had quit in 1997. ${ }^{2}$ Intention to quit among adult smokers in the developed world is as high as $75 \%,{ }^{16}$ while in the developing world it is generally much lower $(14-16 \%$ in China and $31 \%$ in India) ${ }^{17-19}$ This may be related to historical differences in smoking between the developed countries (where prevalence is declining) and developing countries (where prevalence is still increasing). Lopez and colleagues divided the tobacco epidemic into four different stages $^{36}$ :

- Stage 1: smoking prevalence less than 15\% for men and below 5\% for women (the developing countries in subSaharan Africa are now in this stage).

- Stage 2: smoking prevalence $50-80 \%$ in men and increasing in women (China, Japan, and a number of other countries in Asia, Latin America, and North Africa are now in this stage).

- Stage 3: smoking prevalence declines to about $40 \%$ in men; in women smoking prevalence peaks, plateaus, and then starts to decline (Eastern European and Southern European countries are now in this stage).

- Stage 4: smoking rates slowly decline in both sexes; male mortality from smoking peaks and female mortality begins to rise rapidly (USA, Canada, Australia, and developed countries of Western Europe are now in this stage).

Promoting smoking cessation, creating an environment supportive of non-smoking, and providing appropriate services has produced encouraging results in the UK, ${ }^{37}$ the US, $^{38}$ and Hong Kong. ${ }^{39}$ Although in 2000 the WHO recommended that the treatment of tobacco dependence be considered a public health priority, ${ }^{40}$ much more needs to be done to promote smoking cessation in the countries of the developing world.

\section{OBSTACLES TO PROMOTING SMOKING CESSATION IN DEVELOPING COUNTRIES}

Important obstacles to the promotion of smoking cessation in developing countries include:

- economic factors;

- lack of awareness by policy makers of the health consequences and costs of tobacco;

- low perception of risks among the public;

- lack of policies that promote cessation;

- smoking behaviour of service providers and their own lack of knowledge or awareness;

- poor healthcare systems;

- lack of infrastructure; and

- industry action. 
Economic barriers: governmental and individual

To help with their debt burden, many low income countries are shifting towards exportable cash crops including tobacco. ${ }^{41}$ Tobacco is grown in 80 developing countries, in which production increased $128 \%$ from 1975 to $1998 .^{42}$ Tobacco companies are also investing in developing countries by building manufacturing plants. ${ }^{41}$ The economic impact of the tobacco industry can be substantial-for example, major exporters of tobacco leaf such as Malawi, Zimbabwe, and Tanzania receive $60 \%, 23 \%$, and $4 \%$, respectively, of their total export earnings from tobacco. ${ }^{41}{ }^{42}$ These economic forces work against implementing strong tobacco control policies and programmes. However, the impact of the tobacco economy is often overestimated; even in Africa, most countries spend more on tobacco imports than they earn from exports. ${ }^{41}$ For net importers a reduction in tobacco use would be expected to create jobs overall-for example, Bangladesh has reported increasing employment with lower tobacco demand. ${ }^{42}$ In developing countries the average foreign exchange earnings from tobacco are $0.16 \%$ of gross domestic product. ${ }^{34}$ Thus, in most countries, even very stringent tobacco control efforts will have minimal negative economic effects. ${ }^{42}$ In net exporters such as India, Kenya, Malwai, Tanzania, and Zimbabwe, however, tobacco control efforts could have a negative economic impact; the greatest impact would be in the few countries with a significant share of foreign earnings from tobacco, chiefly Malawi and Zimbabwe. $^{42}$

In low income countries it may be difficult to implement proven but more expensive interventions such as quit lines, sustained mass media campaigns, insurance coverage for treatment (particularly medication), and research on the local adverse health and economic effects of tobacco. ${ }^{34}$

Low socioeconomic status is also a barrier to accessing health care, medication, or other forms of assistance in quitting, and developed countries have shown an increasing concentration of smoking in the lower socioeconomic groups.$^{43}$ Historically, tobacco use has started in higher social classes, diffused generally through the population, and then become concentrated in the lower social classes as the hazards of tobacco use become more widely understood. ${ }^{3644}$ Correspondingly, patterns of use in countries still in the earlier stages of the tobacco epidemic may be more homogeneous by class than they are in developed countries. Nevertheless, in nearly all countries-both developing and developed-smoking is more common among poor men (as defined by income, education, occupation, or social class) than rich men. In women the relationship between smoking and poverty varies, probably because the onset of tobacco use by women is more recent. ${ }^{45}$

\section{Lack of awareness of health impacts by policy makers and low public perceptions of risk}

In developing countries policy makers may not be aware that tobacco use has adverse consequences, both economically and for health; this lack of information, in turn, hinders tobacco prevention and control efforts in the country. ${ }^{34} \mathrm{~A}$ contributing factor is the lack of local research on the health and economic costs of tobacco, ${ }^{34}$ and an inappropriate belief of policy makers that tobacco control interventions are less urgent than action on other diseases. ${ }^{41}$

In low income countries public awareness of the health hazards of tobacco is also low. ${ }^{46}$ In 1996 two thirds of adult Chinese smokers believed cigarettes did "little or no harm". ${ }^{18}$ In addition, low education levels in many developing countries may make it harder for people to understand the hazards of tobacco use. ${ }^{47}$ The lack of local studies showing harm also impairs dissemination of health information. ${ }^{47}$ Even when such information is disseminated, people under- estimate the risk of smoking compared with other causes of death. ${ }^{46}$ Studies in the US also demonstrate an inadequate understanding of the addictive properties of tobacco use $\mathrm{e}^{4647}$ and show that, at least early on, smokers often think they can quit smoking whenever they wish. ${ }^{8}$ In addition, the public is frequently unaware of the availability of treatments for tobacco dependence ${ }^{48}$ These data suggest that smokers need to be informed of the dangers of tobacco use and the health promoting aspects of cessation and encouraged to seek assistance if they have difficulty in quitting.

\section{Lack of policies that support cessation}

Tobacco control efforts in the developing world have mostly concentrated on increasing tobacco taxes, restricting or banning advertising, adding or expanding warning messages, and restricting smoking in certain venues, but implementation of these policies has been limited.$^{41}$ For example, in the Western Pacific region, 20 of the 31 nations have legislation that directly or indirectly bans tobacco advertising, promotion and sponsorship (but many of these are only partial bans which have not been shown to be effective); 20 require health warnings; and only 10 have regulations regarding ingredient disclosure and tar and nicotine levels. The taxation policies in the region are widely variable (with very high tax rates only in Singapore and Hong Kong), but almost all countries have laws banning smoking in selected venues. ${ }^{41}$ Because these interventions are often limited in scope and exist in only a few countries, expansion of these policy initiatives will be critical to reversing the epidemic in tobacco related morbidity and mortality unfolding in the developing world. However, enforcement of laws banning smoking is important to retain success of this intervention.

\section{Smoking behaviour and lack of knowledge of the adverse effects of tobacco among service providers} The relatively few studies available describe high levels of smoking among healthcare professions in developing countries. For example, in 1999, 37\% of Algerian medical students smoked; ${ }^{49}$ earlier studies found rates of $61 \%$ (in 1996) for physicians from a hospital in Wuhan, China; ${ }^{.0} 54 \%$ (in 1986) for hospital workers in Nairobi; ${ }^{51}$ and $46 \%$ (in 1980) for male physicians in a region of Sudan. ${ }^{52}$ Smoking by health professionals is a barrier to implementing cessation interventions in the healthcare system since service providers are key to initiating, designing, and implementing any such programme. Even if these clinicians assess smoking status and provide advice, they may not be seen as credible if their patients know they smoke.

Health professionals in developing countries, as is frequently true for policy makers and the general public, are often poorly informed about the health impacts of tobacco. The lack of country specific research data and a failure to disseminate information through official reports contributes to their lack of knowledge and a potential complacency about tobacco as a health issue. ${ }^{47}$ Competing health priorities, particularly those where the health effect is more proximal in time to the behaviour, ${ }^{47}$ also contribute to a lack of action by health providers. For example, in Africa deaths from the HIV/ AIDS epidemic outstrip those from tobacco and are perceived as a more immediate problem. ${ }^{41}$

\section{Deficiencies in the healthcare system and its infrastructure}

The inadequate organisation of the public health system in many developing countries contributes to the general lack of information about the extent to which tobacco use causes harm. Political instability in some countries also works against public health action. In addition, the healthcare infrastructure in developing countries often lacks adequate record keeping, inhibiting the ability of the public health 
community to demonstrate the magnitude of the tobacco problem. An improved vital statistics system, for example, is critical to the documentation of deaths due to tobacco. ${ }^{32}$ Finally, healthcare systems in both developing and developed countries are not structured to effectively care for people with chronic diseases. ${ }^{53}$

The guideline on the clinical treatment of tobacco use developed by the US Public Health Service (USPHS) ${ }^{22}$ suggests implementation of the "5As" approach:

- Ask (about tobacco use);

- Advise (users to quit);

- Assess (interest in quitting);

- Assist (the quit attempt); and

- Arrange (follow up).

In developing countries, however, providers are generally unfamiliar with such brief clinical interventions and many developing countries do not have an integrated system of care that can implement the necessary system changes or provide information and support to the providers. Thus, reaching a large proportion of smokers through the healthcare systems may be difficult.

Efforts are currently underway to reach healthcare providers worldwide through Internet based dissemination of information ${ }^{54}$ and training. ${ }^{55}$ Some training has also been accomplished through conference venues such as the World Conference on Tobacco or Health. ${ }^{56}$ Unfortunately, an inability to access these types of support could slow the dissemination of clinical best practices to developing countries.

\section{Lack of general infrastructure}

In many developing countries progress is hindered by a lack of technology and a weak infrastructure. In many developed countries telephone counselling using quit lines, for example, has proved effective, ${ }^{22}{ }^{2757}$ and California's statewide quit line has been shown in several studies to double quit rates, ${ }^{57}{ }^{58}$ but such an approach may not be feasible in a developing country. If much of the population does not have a home telephone, and existing telephone lines may not be always accessible, such a strategy would not be practical. It would be even more difficult to encourage smokers to use such services if fees were charged, but the government might not be in a position to deliver free cessation services and medications because of the financial constraints mentioned above.

\section{Industry action}

While the public health community is busy trying to reduce tobacco use, the tobacco industry continues to market its products aggressively. Advertising invokes themes of individual rights, independence, and modernisation. Advertisers attempts to "create a fantasy of sophistication, pleasure, and social success" ${ }^{28}{ }^{59}$ In developing countries the fantasy being sold is often American or European culture. ${ }^{28} 59$ For example, in many Asian cities beautiful models promote free Western brand tobacco and other giveaways associated with the West in restaurants, bars and discos. ${ }^{60}$ Data are mixed on the effect of advertising on increasing tobacco consumption, but the stronger studies appear to show a small increase in consumption with advertising. ${ }^{26}{ }^{28}$ The tobacco industry has increased its advertising in conjunction with expanded tobacco control programmes, and a California study suggested that such actions reduced the effectiveness of such a programme. ${ }^{34}$ The industry has also sponsored youth antismoking campaigns. For example, in 2001 the Hong Kong tobacco industry sponsored a youth tobacco prevention programme with a 3 year budget of HK\$18 million (US\$2.31 million). Data from the US, however, suggest that such industry sponsored interventions are not effective in reducing youth smoking and may even lead to increases in such behaviour. ${ }^{61}$

Industry lobbying can also impede action on tobacco prevention and control policies. In the Czech Republic the tobacco industry commissioned an economic analysis for policy makers which reported that smoking cigarettes could save the government money (through early deaths that eliminate pension costs). ${ }^{62}$ Recent convictions of former industry executives in the USA and in Hong Kong provide evidence of industry involvement in smuggling. ${ }^{35}$

The industry also minimises the health impacts of tobacco, even in developed countries where the problem has been well documented. ${ }^{6364}$ For example, in depositions in 2002 to the US Department of Justice, tobacco industry chief executive officers stated that they did not believe there was proof that smoking causes disease or that nicotine is addictive. ${ }^{63}$

\section{WHAT PUBLIC HEALTH AND OTHER HEALTHCARE PROFESSIONALS SHOULD AND COULD DO}

Public health professionals can contribute to policy making by identifying important health problems caused by tobacco, providing evidence of the effectiveness of specific cessation interventions, and suggesting appropriate models for implementing them. Implementation will require collaboration of multiple sectors. Public health professionals should not limit themselves to medical approaches and should consider broader policy approaches as well.

\section{Cessation interventions targeting health professionals} Interventions to reduce smoking among healthcare providers are an important first step. As already mentioned, the prevalence of smoking is high among medical professionals and teachers in some developing countries (such as China). ${ }^{1865}$ Thus, any cessation strategy should attempt to reach these population groups first, so that they can serve as role models for others and also promote cessation services in healthcare settings and schools. Although reaching these groups may require some resources, it is essential if progress is to be made.

\section{Strengthening national commitment}

Strengthening the commitment of the national government is essential to implementing a more comprehensive approach to cessation in both developed and developing countries. This could be done by developing a broader policy framework including a mix of three main strategies: a public health approach; a health systems approach; and a surveillance, research and information approach. ${ }^{31}$ Brazil, Thailand, Qatar, and South Korea have made a strong commitment to controlling tobacco using different strategies which include training of smoking cessation service providers in Thailand, ${ }^{32}$ a demonstration project under the "Healthy City" campaign in South Korea, ${ }^{66}$ smoking cessation clinics in Qatar, ${ }^{31}$ and highlighting of smoking cessation as a key policy within the National Tobacco Control Programmes in Brazil. ${ }^{31}$ Combining objectives for tobacco control with political commitment could accelerate action. In Uganda, for example, the 50\% reduction in the seroprevalence of HIV over 4 years was accomplished with this strategy. ${ }^{67}$

\section{Developing a model for developing countries}

There is no single cessation model in developed countries, ${ }^{263032406869}$ but country specific models generally consist of a selection of strategies such as price increases, media campaigns, smoke free policies, reducing the out-of-pocket costs of treatment, providing counselling and medication through the healthcare system, telephone quit lines, advertising bans, and stronger warning labels. Policies reach large numbers of people and can change social norms around 
tobacco use. ${ }^{26}{ }^{27}$ In general, effective policies are very cost effective and some are revenue generating (taxation). ${ }^{70}$ In addition, some policies (such as taxation) may both increase cessation and decrease initiation, ${ }^{26}{ }^{27}$ creating further efficiencies. However, the smoking cessation models used in developed countries may have mixed applicability in the developing world. Although many policy changes (such as increased tobacco taxes, smoke free policies, advertising bans, stronger warning labels, and smuggling controls) can be applied in most countries, more costly interventions (such as telephone quit lines, sustained paid mass media campaigns, and provision of medication) may have limited applicability in the developing world. ${ }^{32}$ In addition, interventions through the healthcare system may be limited by high smoking rates among healthcare providers, competing health priorities, and lack of awareness of the adverse health and economic costs of tobacco use. Thus, any model should be tested locally for its applicability, acceptance and effectiveness, particularly in resource poor settings. Population specific programmes ${ }^{71-74}$ that are culturally sensitive have been effective among different population groups elsewhere. Moreover, the social marketing role of radio and television networks-for example, the Star television network of Singapore and the Bollywood television industry-could also be tested as potential vehicles to promote smoking cessation in developing countries, which was very effective for promoting condom use in Asia and Africa.

\section{Changing the social acceptability of smoking}

Some societies still consider smoking to be an indication of higher social class and, in China and Vietnam, many people buy cigarettes as a gift for superiors or older members of the family. Its addictive qualities notwithstanding, tobacco use is strongly influenced by the social conventions, customs, and norms of society or population groups within a country ${ }^{26} 7576$ and is subject to changes in the social environment. ${ }^{26} 73$ Encouraging people to stop smoking is unlikely to have an optimal impact unless efforts are made simultaneously to promote social norms that support cessation; countermarketing campaigns, media advocacy, and smoke free policies are important tools for changing such norms. ${ }^{26} 307375$ Initiatives to change the societal values towards tobacco use must therefore be a priority. Initiatives to increase awareness of the hazards of tobacco use are possible in developing countries, particularly lower cost efforts such as official reports and requiring or strengthening warning labels on tobacco products. ${ }^{46}$ Higher cost initiatives such as sustained mass media campaigns may be more difficult. ${ }^{32}$

\section{Strengthening community participation}

Data on community interventions come primarily from developed countries. ${ }^{25} 2632$ Ideally, community programmes should be comprehensive and intervene through multiple social structures. ${ }^{26} 3075$ In the US the Arizona cessation plan (which requires linkage between community cessation services and the telephone quit line) increased the amount of advice to quit given by healthcare providers and reduced the prevalence of smoking. ${ }^{77}$ The tobacco prevention and control programme in Massachusetts, which included a mass media campaign, quit line, and community cessation programmes, has doubled the percentage of smokers planning to quit in the next 30 days in 4 years. ${ }^{78}$ Community intervention programmes in developing countries such as India (community intervention consisting of health professional advice, mass media campaign, and cessation camps), ${ }^{79}$ South Africa (which requires community members to be trained to deliver smoking cessation programmes and specific advice to smokers), ${ }^{80}$ and Fiji (longer term collaborative and village empowerment methods $)^{81}$ were effective in promoting quitting smoking.
The World Bank estimated the cost of essential interventions (including tobacco control) at $\$ 4$ per capita in low income countries, ${ }^{34}$ so comprehensive community interventions may not be feasible in developing countries without the provision of additional resources. ${ }^{34}$ Smaller scale efforts by community based organisations or health centres could promote smoking cessation by (1) promoting a smoke free environment, (2) providing social support to smokers as they try to quit and, in some cases, (3) financing nicotine dependence treatments for the poor. Volunteers in religious centres such as mosques and churches could also provide brief counselling for cessation.

\section{Integrating smoking cessation service with other healthcare services}

Conducting local research on the hazards of tobacco use is moderately feasible in developing countries but may require outside resources. ${ }^{34}$ The National Institutes of Health Fogarty Center tobacco grants ${ }^{82}$ are an example of this type of assistance for developing local research capacity. This grant programme supports international cooperation between investigators in the US and other high income nations and scientists and low and/or middle income nations; the major portion of the research must be conducted in a low or middle income country and more than $50 \%$ of the direct costs must be used in the low or middle income nation(s) for research or strengthening the research capacity of foreign institutions.

Because developing countries face enormous financial difficulties in merely maintaining their existing healthcare services and the experience in the US suggests that targeted smoking cessation clinics are not well used and have limited impact, ${ }^{83}$ it might be more feasible and cost effective for them to integrate smoking cessation into other healthcare programmes such as tuberculosis, HIV/AIDS, cancer control, cardiovascular disease control, or family planning and maternal health. ${ }^{34}$ Where self-medication and relying on pharmacists for health information is common, brief counselling interventions by pharmacists could be another early strategy. ${ }^{25}$ Providing smoking cessation services such as counselling, medication, education materials, and follow up arrangements in the same way as interventions for other chronic diseases ${ }^{22}{ }^{85}$ may be a way of integrating treatment for smoking into the general delivery of health care. Publicprivate collaboration would be useful in this regard.

\section{Specifying the role of healthcare professionals}

Helping health professionals (doctors, nurses, physiotherapists) to understand the addictive properties of tobacco is important in making them appreciate the need for treatment and the key role that healthcare providers play in increasing cessation rates. As in many countries in the West, ${ }^{86}$ smoking cessation is not included in the educational curriculum of medical or other health professionals in many developing countries. ${ }^{87}$ As a result, health professionals often lack the expertise to deal with tobacco.

Studies have shown that simple advice to quit smoking is an effective intervention; it is also one that can be effectively provided by a variety of health professionals. ${ }^{22}$ In developing countries an attempt should be made to encourage health professionals of all types (such as pharmacists) to identify tobacco users and provide brief advice to quit, in spite of the challenges imposed by the fragmented healthcare systems in these countries. Service providers and policy makers need to determine how to integrate brief cessation advice and more intensive cessation services and products within the health service delivery system in resource poor countries and how to encourage people to use these services. Hospitals may be a good setting in which to begin since patients receive treatment in a more systematic way in this setting. 


\section{Developing guidelines}

The development of practice guidelines by professional groups encourages clinicians to maintain certain standards in their service delivery. ${ }^{88}$ Several available guidelines make recommendations for intervening with tobacco users, ${ }^{21-23}$ but local guidelines are often viewed as desirable as they encourage local providers to "buy into" them. Not surprisingly, however, few guidelines on the treatment of smoking have been created within developing countries; if a decision is made to draft them, it is important that different sectors (various healthcare professionals and healthcare system administrators, both public and private) be included in the process.

\section{Mobilising the business community}

The business community requires a strong workforce, and reducing the number of smokers in the workplace would mean potential savings from decreased absences for smoking related illness, reduced costs for hospitalisation, and lower retraining costs due to early deaths. ${ }^{49}$ Workplace strategies for other purposes have a good track record in some developing countries in Asia; China, for example, has a sophisticated workplace population control programme which has dramatically affected its demographic transition. ${ }^{90}$ In Thailand a business coalition on AIDS established in 1993 offers a workplace HIV education programme to each tier within the business organisation. ${ }^{91}$ Similar programmes have been effective in promoting HIV prevention campaigns among African populations..$^{92}$ Mobilising the business community to promote smoking cessation could potentially improve the reach and impact of cessation interventions.

\section{Financial incentives}

An important factor to consider is whether smokers should have to pay for cessation counselling or medication. In many developing countries the price of nicotine replacement therapy is high. ${ }^{25}$ Studies have shown that reducing the out-of-pocket cost of treatment increases both the use of treatment and number of successful quitters. ${ }^{27} 93$ Although the cost of pharmaceuticals is a major barrier for resource poor countries, data show that treatment (including medication) is cost effective even in low income countries. ${ }^{25}$ The price of medication varies widely by country; ${ }^{25}$ government negotiation to reduce the price of tobacco cessation medications in resource poor countries, which would parallel earlier actions on antiretroviral drugs, is one option. ${ }^{94}$ Waiving the government tax on medications or producing them locally, as has been done in China in the case of antiretroviral drugs for HIV, is another option. ${ }^{95}$ Still another strategy is to include at least one medication for tobacco treatment on the WHO list of essential drugs.

\section{Collaboration between countries}

Developing countries should initiate smoking cessation programmes within the framework of the individual country's needs and available resources, and should share their strategies with other countries with similar socioeconomic and cultural backgrounds. Research on effective approaches could be translated into nationwide programmes and policies. International funding support would most likely be necessary to help develop any initial programmes, as most countries in the developing world do not have enough resources to initiate extensive programmes.

\section{International initiatives}

International collaboration will be crucial in promoting smoking cessation in the developing world. Most developing countries are resource poor and their governments may not consider smoking cessation a high priority when compared with other pressing problems. The WHO, World Bank,
International Monetary Fund (IMF), Gates Foundation, and other global institutions could promote the importance of cessation and support initiatives (particularly policy initiatives) to increase cessation in developing countries. For example, it has been proposed that international agencies could make the existence of tobacco control policies a condition of financial packages. ${ }^{34}$ Initiatives with a multinational focus are other options. As an example of an ongoing project, a global cessation media campaign is being developed in conjunction with WHO. ${ }^{96}$ Developing a multinationally funded initiative is another option. ${ }^{97}$ The WHO Framework Convention on Tobacco Control could play a crucial role in taking these initiatives. However, any international initiative should not undermine the resources badly needed to support many more pressing threats posed by infectious diseases such as HIV, tuberculosis, and malaria in many developing countries.

\section{CONCLUSION}

Policy makers should be informed that tobacco control is essential to improve population health and that even modest reductions in the disease burden of tobacco will bring highly significant gains. Cessation is vital to any tobacco control programme. Some immediate actions are possible, such as expanding smoke free policies, increasing taxes on tobacco products, implementing or strengthening warning labels, targeting physicians and teachers for cessation interventions, and integrating brief counselling into other healthcare services (such as maternal and child health, tuberculosis, and HIV programmes). Interventions that have significant associated costs, however-such as quit lines, reducing the cost of medication, and sustained media campaigns-may require dedicated funding from tobacco taxes or international assistance. ${ }^{34}$ Experience in developed countries has shown that involvement of the private sector and other interest groups can lead to successful policy change. ${ }^{98}$ Policy initiatives should be integrated with community wide tobacco control interventions that focus on employers, health providers, and the community. ${ }^{75}$ International bodies such as WHO, the World Bank, the IMF, or the Gates Foundation could initiate pilot projects to promote smoking cessation in the developing world. Lessons learned from the experience of developed countries and any existing current programmes in developing countries should be consulted in designing these programmes. Lessons learned in the development of other public health programmes (such as HIV/ AIDS control programmes) in developing countries should also be used as models. Global support and strong commitment, especially from international organisations and donor agencies, will be crucial. Furthermore, success of a tobacco cessation programme in developing countries will rely greatly on the autonomy and transparency of those organisations that are in a position to initiate and implement these programmes.

\section{ACKNOWLEDGEMENTS}

The authors thank Dr David Wilmshurst (Research Services Section) of the University of Hong Kong (HKU) for his editorial assistance in the earlier draft of the paper and Ms Carrie Yam (Department of Community Medicine, HKU) for her help in preparing the present manuscript.

\section{Authors' affiliations}

A S M Abdullah, Department of Community Medicine, The University of Hong Kong, Hong Kong SAR, China

C G Husten, Office on Smoking and Health, Centers for Disease Control and Prevention (CDC), Atlanta, GA, USA

Conflicts of interest: none 


\section{REFERENCES}

1 United Nations Population Fund (UNFPA). Population and demographic dynamics. www.ufpa.org/population/demogra.htm (accessed 7 April 2003)

2 Gajalakshmi CK, Jha P, Ranon K, et al. Global patterns of smoking and smoking-attributable mortality. In: Jha P, Chaloupka F, eds. Tobacco control in developing countries. New York: Oxford University Press, 2000:1 1-39.

3 World Bank. Curbing the epidemic: government and the economics of tobacco control. Geneva: World Bank, 1999.

4 Ezzati M, Lopez AD. Estimates of global mortality attributable to smoking in 2000. Lancet 2003:362:847-52

5 CDC. Cigarette smoking-attributable morbidity - United States, 2000. Morb Mort Wkly Rep 2004; (in press).

6 Doll R, Peto R, Wheatley K, et al. Mortality in relation to smoking: 40 years' observations on male British doctors. BMJ 1994;309:901-11.

7 Coffield AB, Maciosek MV, McGinnis M, et al. Priorities among recommended clinical preventive services. Am J Prev Med 2001;21:1-9.

8 McGinnis JM, Foege WH. Actual causes of death in the United States. JAMA 1993;270:2207-12.

9 US Department of Health and Human Services. The health benefits of smoking cessation: a report of the Surgeon General. Rockville, MD: US Department of Health and Human Services, Centers for Disease Control, Office on Smoking and Health, 1990

10 Terres W, Becker P, Rosenberg A. Changes in cardiovascular risk profile during the cessation of smoking. Am J Med 1994:97:242-9.

11 Commission on Macroeconomics and Health. Macroeconomics and health: investing in health for economic development. www3. who.int/whosis/cmh/ (accessed 22 April 2003).

12 World Health Organization. Draft WHO framework convention on tobacco control. Intergovernmental negotiating body on the WHO Framework Convention on Tobacco Control. Geneva: WHO, March 2003; www. who.int/ $\mathrm{gb} / \mathrm{fctc} / \mathrm{PDF} / \mathrm{inb} 6 /$ einb65.pdf (accessed 22 April 2003).

13 World Health Organization. International statistical classification of diseases and related health problems, 10th ed. Geneva: World Health Organization, 1994.

14 American Psychiatric Association. Diagnostic and statistical manual of mental disorders, 4th ed. Washington, DC: American Psychiatric Association, 1994

15 CDC. Cigarette smoking among adults - United States, 1995. MMWR Morb Mortal Wkly Rep 1997;46:1217-20.

16 CDC. Cigarette smoking among adults - United States, 2000. MMWR Morb Mortal Wkly Rep 2002;51:642-5.

17 Gupta PC. Is your population addicted? Cross country comparison of tobacco addiction and readiness to quit-global tobacco control implications. Satellite symposium at the 11 th World Conference on Tobacco or Health, August 2000, Chicago, USA.

18 Yang G, Lixin F, Tan J, et al. Smoking in China: findings of the 1996 national prevalence survey. JAMA 1999:282:1247-53.

19 Yang G, Ma J, Chen A, et al. Smoking cessation in China: findings from the 1996 national prevalence survey. Tobacco Control 2001;10:170-4.

20 US Department of Health and Human Services. The health consequences of smoking: nicotine addiction. A report of the Surgeon General. Atlanta, GA US Department of Health and Human Services, Centers for Disease Control and Prevention, Office on Smoking and Health, 1988

21 West R, McNeill A, Raw M. Smoking cessation guidelines for health professionals: an update. Thorax 2000;55:987-99.

22 Fiore MC, Bailey WC, Cohen SJ, et al. Treating tobacco use and dependence. Clinical practice guideline. Rockville, MD: US Department of Health and Human Services, 2000.

23 Lancaster T, Stead L, Snowden A, et al. Cochrane Tobacco Addiction Group. In: The Cochrane Library, Issue 2, 2002. www.dphpc.ox.ac.uk/cochranetobacco/ (accessed 20 May 2002).

24 US Preventive Services Task Force. Guide to clinical preventive services, 3rd ed. Rockville, MD: US Department of Health and Human Services, 2002. www.ahra.gov/clinic/cps3dix.htm (accessed 7 May 2002)

25 Novotny TE, Cohen JC, Yurekli A, et al. Smoking cessation and nicotinereplacement therapies. In: Jha P, Chaloupka F, eds. Tobacco control in developing countries. New York: Oxford University Press, 2000:287-307.

26 US Department of Health and Human Services. Reducing tobacco use: a report of the Surgeon General. Atlanta, GA: US Department of Health and Human Services, Centers for Disease Control and Prevention, Office on Smoking and Health, 2000. www.cdc.gov/tobacco/sgr_tobacco_use.htm (accessed 3 May 2002)

27 Hopkins DP, Briss PA, Ricard CJ, et al. Reviews of evidence regarding interventions to reduce tobacco use and exposure to environmental tobacco smoke. Am J Prev Med 2001;20(Suppl 2): 16-66.

28 Saffer $\mathbf{H}$. Tobacco advertising and promotion. In: Jha P, Chaloupka F, eds. Tobacco control in developing countries. New York: Oxford University Press, 2000:213-36.

29 Chaloupka FJ, Hu T-W, Warner KE, et al. The taxation of tobacco products. In: Jha P, Chaloupka F, eds. Tobacco control in developing countries. New York: Oxford University Press, 2000:235-72.

30 CDC. Best practices for comprehensive tobacco control programs - August 1999. Atlanta, GA: US Department of Health and Human Services, Centers for Disease Control and Prevention, Office on Smoking and Health, 1999. www.cdc.gov/tobacco/bestprac.htm (accessed 23 May 2002)

31 World Health Organization. Tools for advancing tobacco control in the XXIst century: policy recommendations for smoking cessation and treatment of tobacco dependence. Geneva: World Health Organization, 2003:4-41.

32 World Health Organization. Tools for advancing tobacco control in the XXIst century: policy recommendations for smoking cessation and treatment of tobacco dependence. Geneva: World Health Organization, 2003:53.
33 Fichtenberg CM, Glantz A. Effect of smokefree workplaces on smoking behavior: systematic review. BMJ 2002;325:188-94.

34 Jha $P$, Paccaud F, Nguyen S. Strategic priorities in tobacco control for governments and international agencies. In: Jha P, Chaloupka F, eds. Tobacco control in developing countries. New York: Oxford University Press, 2000:449-64.

35 Joossens L, Chaloupka FJ, Merriman D, et al. Issues in the smuggling of tobacco products. In: Jha P, Chaloupka F, eds. Tobacco control in developing countries. New York: Oxford University Press, 2000:393-406.

36 Lopez AD, Collishaw NE, Piha T. A descriptive model of the cigarette epidemic in developed countries. Tobacco Control 1994;3:242-7.

37 Owen L. Impact of a telephone helpline for smokers who called during a mass media campaign. Tobacco Control 2000:9:148-54.

38 McAfee T, Wilson J, Dacey S, et al. Awakening the sleeping giant: mainstreaming efforts to decrease tobacco use in an HMO. HMO Pract 1995: 138-43.

39 Hedley AJ, Abdullah ASM, Lam TH, et al. Impact of smoking cessation services on smokers in Hong Kong and predictors of successful quitting QUIT.COM, a publication on the treatment of tobacco dependency, Hong Kong Council on Smoking and Health, Hong Kong. 2001;2:1-8.

40 World Health Organization Europe. Partnership to reduce tobacco dependence. Copenhagen: World Health Organization, 2000.

41 Corrao MA, Guindon Ge, Sharma N, Shokoohi DF, eds. Tobacco control country profiles. Atlanta, GA: American Cancer Society, 2000

42 Jacobs R, Gale HF, Capehart TC, et al. The supply-side effects of tobacco control policies. In: Jha P. Chaloupka F, eds. Tobacco control in developing countries. New York: Oxford University Press, 2000:31 1-41.

43 Hill DJ, White VM, Scollo MM. Smoking behaviours of Australian adults in 1995: trends and concerns. Med J Aust 1998;168:209-13.

44 Cavelaars AE, Kunst AE, Geurts JJ, et al. Educational differences in smoking: international comparison. BMJ 2000; 320:1 102-7.

45 Bobak M, Jha P, Nguyen S, et al. Poverty and smoking. In: Jha P, Chaloupka F, eds. Tobacco control in developing countries. New York: Oxford University Press, 2000:41-61

46 Kendel D, Chen L. Consumer information and tobacco use. In: Jha P, Chaloupka f, eds. Tobacco control in developing countries. New York: Oxford University Press, 2000:178-214

47 Jha P, Musgrove P, Chaloupka FJ, et al. The economic rationale for intervention in the tobacco market. In: Jha P, Chaloupka F, eds. Tobacco control in developing countries. New York: Oxford University Press, 2000:153-74.

48 Zhu S-H. California smokers' helpline: an accessible service for a diverse population. In: Wellness Lecture Series. Berkeley, CA: University of California Printing, 1996:55-73.

49 Tessier JF, Noijari C, Bennani-Othman M. Smoking in Mediterranean countries: Europe, North Africa and the Middle-East. Results from a cooperative study. Int J Tuberc Lung Dis 1999;3:927-37.

$50 \mathrm{Li} \mathrm{HZ}$. Increases in cigarette smoking and decline of anti-smoking counselling among Chinese physicians. Health Promot Int 1999;14:123-31.

51 Lore W, Lwenya R. Smoking habits in Kenya II: a follow up study involving personnel working at Kenyatte National Hospital, Nairobi. East Afr Med J 1988:65:71-80.

52 Ballal SG. Cigarette smoking and respiratory symptoms among Sudanese doctors. East Afr Med J 1984;2:95-103.

53 World Health Organization. Innovative care for chronic conditions. World Health Organization, Noncommunicable Diseases and Mental Health. Meeting report, May 2001. www.who.int/chronic conditions/ lcccmeeting.pdf.

54 World Health Organization. Treatobacco.net: database and educational resource for treatment of tobacco dependence. www.treatobacco.net (accessed 4 April 2003).

55 University of Wisconsin. Online CME @ the University of Wisconsin. Treating tobacco use and dependence. www.cme.uwisc.org/ index.pl?op = show;id $=6620$ (accessed 4 April 2003).

56 Fiore M, Hurt R, Rigotti N, et al. Smoking cessation. Chicago, IL: World Conference, 2000.

57 Zhu SH, Anderson CM, Johnson CE, et al. A centralised telephone service for tobacco cessation: the California experience. Tobacco Control 2000;9(Suppl II):ii48-ii55.

58 Zhu S- H, Anderson CM, Tedeschi GJ, et al. Evidence of real-world effectiveness of a telephone quitline for smokers. N Engl J Med 2002;347:1087-93

59 US Department of Health and Human Services. Women and smoking: a report of the Surgeon General. Rockville, MD: US Department of Health and Human Services, Public Health Service, Centers for Disease Control and Prevention, Office on Smoking and Health, 2001. www.cdc.gov/tobacco/ sgr_forwomen.htm (accessed 18 April 2003).

60 Abdullah ASM. Changing the tobacco trend in China. Lancet 2000;356:432-3.

61 Farrelley MC, Healton CG, Davis KC, et al. Getting to the truth: evaluating national tobacco countermarketing campaigns. Am J Public Health 2002;92:901-7.

62 The New York Times. Philip Morris issues apology for Czech study on smoking. The New York Times 27 July 2001, 12 .

63 Waxman HA. Tobacco industry statements in the US Department of Justice lawsuit. Tobacco Control 2003;12:94-101.

64 Shamasunder B, Bero L. Financial ties and conflicts of interest between pharmaceutical and tobacco companies. JAMA 2002;288:738-44.

65 Chapman S, Leng WW. Tobacco control in the third world: a resource atlas. Penang, Malaysia: International Organization of Consumers Unions, 1990. 
$66 \mathrm{Kim} \mathrm{HJ}$. Healthy city kwachon 21 project: a community health promotion programme in Korea. Asia Pacific J Public Health 2000; 12:S67-70.

67 Anon. Uganda tackles AIDS from the very top down. Aids Alert 1999;14:3-4.

68 Interagency Committee on Tobacco. Preventing 3 million premature deaths, helping 5 million smokers quit: a national action plan for tobacco cessation. Washington, DC: Interagency Committee on Tobacco, Cessation Subcommittee, 2003.

69 Da Costa L, Goldfarb S. Government leadership in tobacco control: Brazil's experience 2004; (in press).

70 Ranson $\mathrm{K}$, Jha $\mathrm{P}$, Chaloupka FJ, et al. The effectiveness and cost-effectiveness of price increases and other tobacco control policies. In: Jha P, Chaloupka F, eds. Tobacco control in developing countries. New York: Oxford University Press, 2000:427-47.

71 Agency for Healthcare Research and Quality. Informacion en espanol. www.ahrq.gov/consumer/espanoix.htm (accessed 29 May 2003).

72 California Smokers Helpline. www.californiasmokershelpline.org/how $/ \mathrm{htm}$ (accessed 4 April 2003).

73 Independent Evaluation Consortium. Final report of the independent evaluation of the California Tobacco Control Prevention and Education Program: Wave 1 data, 1996-97. Rockville, MD: The Gallup Organization 1998.

74 Fox Chase Cancer Center. Pathways to freedom: winning the fight against tobacco. Philadelphia, PA: Fox Chase Cancer Center, 1992

75 National Cancer Institute. Monograph 1: Strategies to control tobacco use in the United States: A blueprint for public health action in the 1990s. NIH Publication No. 92-3316. Rockville, MD: US Department of Health and Human Service, Public Health Services, National Institutes of Health, 1991.

76 CDC. Prevalence of current cigarette smoking among adults and changes in prevalence of current and some day smoking-United States, 1996-2001. MMWR Morb Mortal Wkly Rep 2003;52:303-7.

77 CDC. Tobacco use among adults - Arizona, 1996 and 1999. MMWR Morb Mortal Wkly Rep 2001;50:402-6.

78 Abt Associates Inc. Independent evaluation of the Massachusetts tobacco control program. Fourth annual report. MA: Abt Associates Inc, 1997.

79 Gupta PC, Mehta FS, Pindborg JJ, et al. Intervention study for primary prevention of oral cancer among 36000 Indian tobacco users. Lancet 1986;1:1235-9.

80 Steyn K, Hoffman M, Levitt NS, et al. Community-based tobacco control program: the Mamre study, a demonstration project. Ethn Dis $2001 ; 11: 296-302$.

81 Groth-Marnat G, Leslie S, Renneker M. Tobacco control in a traditional Fijian village: indigenous methods of smoking cessation and relapse prevention. Soc Sci Med 1996:43:473-7.
82 National Institutes of Health. International tobacco and health research and capacity building program. National Institutes of Health, Forgarty International Center. www.fic.nih.gov/programs/tobacco.html (accessed 4 April 2003).

83 Zhu S, Melcer T, Sun J, et al. Smoking cessation with and without assistance: a population-based analysis. Am J Prev Med 2000;18:305-11.

84 Yankelovich Partners Inc. Smoking cessation study. New York: American Lung Association, 1998.

85 Richmond RL, Makinson RJ, Kehoe LA, et al. One-year evaluation of three smoking cessation interventions administered by general practitioners. Addict Behav 1993; 18:187-99.

86 Ferry LH, Grissino LM, Runfola PS. Tobacco dependence curricula in the US undergraduate medical education. JAMA 1999;282:825-9.

87 Richmond R, Larcos D, Debono D. A worldwide survey of teaching about tobacco in medical schools. In: Richmond R, ed. Educating medical students about tobacco planning and implementation. Paris, France: International Union Against Tuberculosis and Lung Disease, 1996:281-96.

88 American Medical Association. How to help patients stop smoking: guidelines for diagnosis and treatment of nicotine dependence. Chicago, IL: American Medical Association, 1994

89 Warner KE, Smith RJ, Smith DG, et al. Health and economic implications of a work-site smoking cessation program: a simulation analysis. J Occup Environ Med 1996;38:981-92.

90 Hesketh T, Zhu WX. Health in China: the one child family policy: the good, the bad, and the ugly. BMJ 1997;314:1685-7.

91 Kimball AM, Thant M. A role for businesses in HIV prevention in Asia. Lancet 1996;347:70-2.

92 Anon. Making AIDS a business imperative. Lancet 1999;354:1.

93 Curry SJ, Grothaus LC, McAfee T, et al. Use and cost effectiveness of smokingcessation services under four insurance plans in a health maintenance organization. N Engl J Med 1998;339:673-9.

94 Ammann AJ, Nogueira S. Governments as facilitators or obstacles in the HIV epidemic. BMJ 2002;324:184-5.

95 Parry J. China makes its first antiretroviral drugs for treating AIDS. BMJ 2002;325: 1257.

96 Schar EH, Gutierrez KK. Smoking cessation media campaigns from around the world: recommendations from lessons learned. Copenhagen: World Health Organization, Regional Office for Europe, 2001

97 Brugha R, Walt G. A global health fund: a leap of faith? BMJ 2001;323:152-4.

98 Bell C, Urbach D. Bartenders' pulmonary function after establishment of a smoke-free workplace. JAMA 1999;282:629. 